\title{
Blended Change Management: Concept and Empirical Investigation of Blending Patterns
}

\author{
Michael REISS \\ BWI, Abt. II, Universität Stuttgart, Keplerstr. 7, Stuttgart, Germany. \\ Email: lehrstuhl.organisation@bwi.uni-stuttgart.de
}

Received September 2, 2009; revised October 11, 2009; accepted November 20, 2009.

\begin{abstract}
In coping with the challenges of revolutionary or evolutionary change processes, change managers do not rely on single tools but on toolboxes containing several domains of tools. The impact of toolboxes on change performance depends both on the complementary inter-domain mix and the intra-domain blending of tools. The patterns of blending are investigated both conceptually and empirically with respect to scope, diversity and coupling of tools. Survey results indicate that blending practices are predominantly determined by rational tool evaluation and by task context.
\end{abstract}

Keywords: Blending, Toolbox, Web Tools, Integration, Blended Change Management

\section{Introduction}

Failure rates of change projects of $50 \%$ and more are a prominent challenge to change managers [1]. Causes of failure have been scrutinized [2-4] and an array of measures to enhance success rates has been developed. There are four interdependent approaches responding to these challenges: The focus of the functional approach is optimized change processes, e.g. better timing of pilot and roll-out phases and parallel instead of sequential communication with managers, employees, customers and other stakeholders affected by the change. The organizational role approach emphasizes the installation of change agents or caretakers, such as champions, sponsors, initiators, implementers, and facilitators [5] as well as the installation of committees to enable participation and empowerment. Skills of agents [6], institutions (e.g. dynamic capabilities [7]), and targets (capacities of learning) are a key success factor in this approach. Finally there is a tool or instrumental approach [8,9]. The tool approach represents the arena of change management with a maximum overlap of scientists' and practitioners' handling of change projects. The overall fund of tools is steadily growing [10]. So are toolboxes in terms of configurations of tools for use in specific change projects. This augmentation is partly due to the activities of change consultancies that develop and use tool innovations as a competitive strategy of differentiation (e.g. tool branding).

Most tools support the implementation of a new concept (i.e. "the" change) into an existing context. Together with the strategy, systems and technology, people represent a generic and ubiquitous area of context. The section of a change management toolbox dedicated to influence attitudes and behaviors of people contains four core domains (see Figure 1). This classification is based upon the primary functionality of the tools, i.e. influencing the acceptance of change from employees, managers, customers, public and other groups affected by the transition.

To make people commit to new behavior and thereby accept or even embrace change both the ability for change (skill factor) and the willingness for change (will factor) must be taken care of. The tool domains of information and instruction complementarily determine the level of skill while involvement and integration determine the will of the people affected. Information and communication tools in change management are supposed to specify the content, the objectives, the consequences, and the progress of a change project. Training is expected to develop the requisite personal competencies, and motivation tools to provide a commitment to the change project. Finally, organization tools such as participation and project organization integrate people actively into the change process by giving them roles they are supposed to play (e.g. project managers, mediators, multiplicators, coaches, etc.). Some tools like workshops or wikis are versatile or multifunctional due to their capacity to inform, skill, motivate, and integrate simultaneously. 


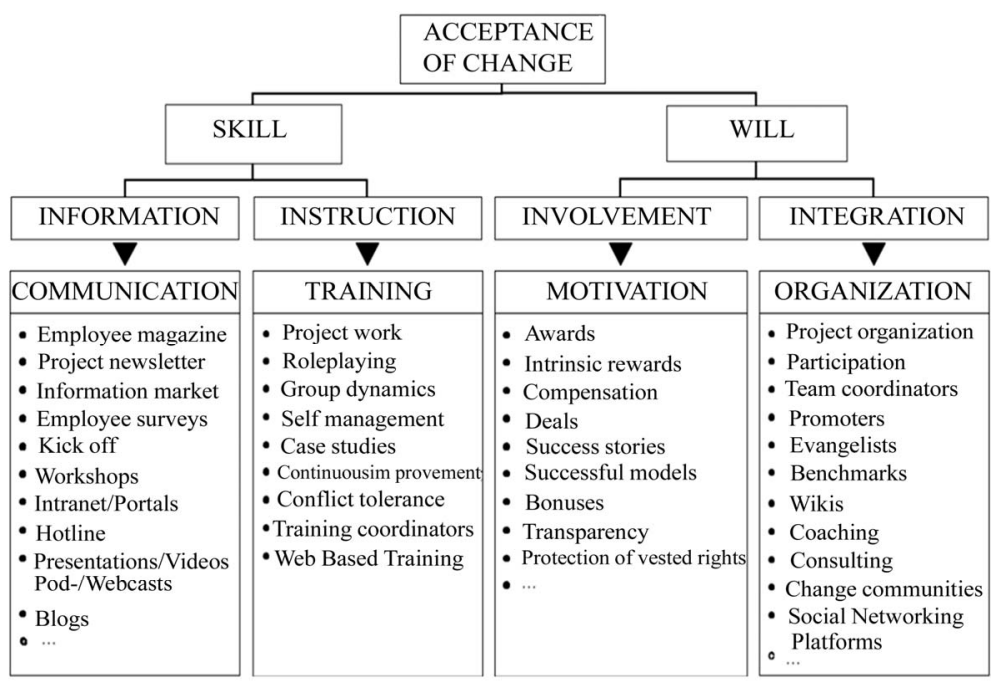

Figure 1. Management tools for enhancing acceptance of change

In addition to the inter-domain mixing of functionally complementary tools (i.e. for information, instruction, motivation, and organization), toolboxes applied in change projects are also the result of intra-domain mixing, i.e. the configuration of functionally identical ("redundant”) tools, such as interactive tools like workshops combined with other interactive tools like bilateral talks and negotiations or print media combined with electronic media. Whenever significantly heterogeneous tools are applied simultaneously, this process and the resulting configuration are mostly called "blending" and "blended" respectively, such as blended learning as a mix of face- to-face- and e-learning [11]. Diversity due to a hybrid configuration is a ubiquitous feature of change management in general (e.g. combining revolutionary and evolutionary changes in so called hybrid systems, [12]) and of tool blending in particular:

1) Change managers often utilize both the potential of participative Organizational Development (OD) tools and of "manipulative" marketing tools (e.g. "selling” change by means of awards, slogans, road shows, "deals”, and advertising).

2) Besides soft factors such as coaching, success stories, persuasion, role and theatre playing [13], hard factors like Balanced Scorecards or milestone planning are quite frequently used [14].

3) Top-down-interventions (e.g. kick-offs, cascading information processes, corporate blogs) are combined with bottom-up-initiatives (e.g. suggestion schemes, continuous improvement process, communities, social software).

4) Change management relies on face-to-face interactions as well as on virtual interactions via electronic media [15].

5) Communication is based on unilateral broadcasting and on interactive environments such as team meetings, open space, workshops and video conferences.

6) Acquisition of requisite skills is accomplished by on the job- and off the job-learning.

7) Hybrid tools of "edutainment" and "infotainment" (e.g. business TV, gaming, [16]) help foster learning motivation.

Hence, every configuration of toolboxes implies numerous blending decisions. The denotation of blending emphasizes its hybrid make-up ("combining extremes”) whereas the connotation of blending refers to the effectiveness of these mixes, captured in slogans like "best of both worlds-combinations”. Blended models outside the management sphere such as blended materials (alloy), beverages or tobacco serve as role models.

\section{The Logic of Blending}

\subsection{Evaluation of Tool Blending: Opportunities and Risks}

Augmentation per se is not a guaranty for enhanced performance and does not automatically mean enrichment. Neither is blending per se the reliable cure of weaknesses and drawbacks of some change management tools. A transfer of lessons learned from other blending arenas-modern arenas such as blended or hybrid learning [17], multimedia, multichannel distribution (brick\&click-or hybrid companies), or diversity management as well as traditional arenas like carrot \& stick-leadership, dual leadership or interactions of intrinsic and extrinsic motivation-indicate that a "more means better" point of view is rather naïve. The message of these lessons reads: blending goes along with several risks of inefficiency or even ineffectiveness, e.g. overload, lack of orientation, high costs and frictions. 


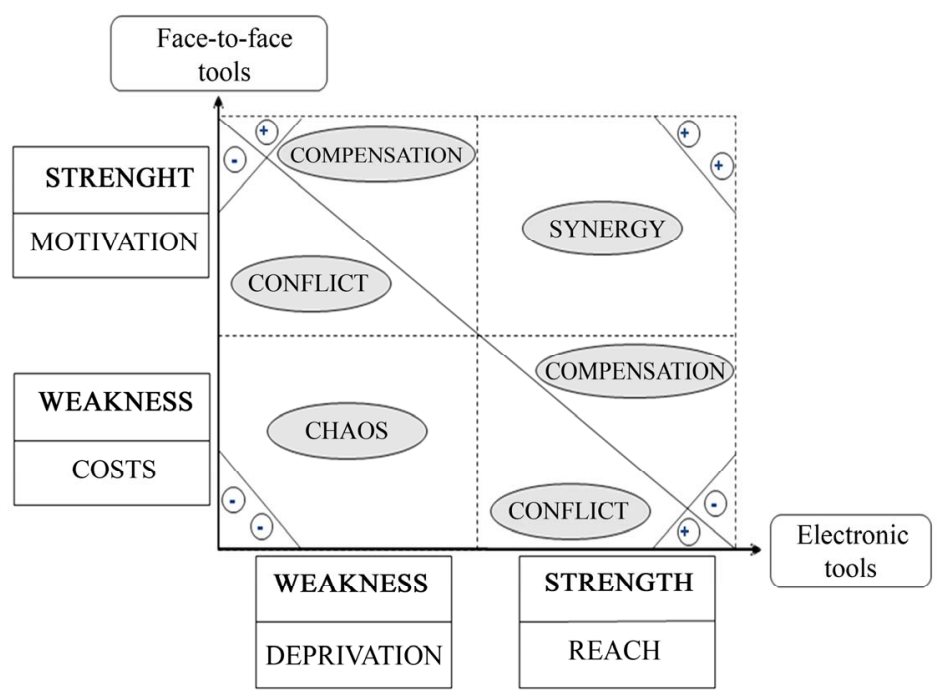

Figure 2. Opportunities and risks of tool blending

To respond to the resulting ambivalent connotation of blending by a simple "blending: bane or boon-approach" turns out to be too superficial. Instead the rational design of toolboxes should follow the principle of "no integration without evaluation”. Evaluation serves as a guide for all activities supposed to amplify opportunities and to mitigate risks related to tool blending. Figure 2 illustrates a simplified evaluation of blending face-to-face tools and electronic tools in change management.

In correspondence to the hybrid character of the object of evaluation, i.e. the mix of online and onsite tools, the evaluation model for blended toolboxes is also based on a hybrid design. The evaluation of the two tool clusters is focused on their respective strengths and weaknesses. Opportunities are the result of the "productive tension" in a hybrid construction (area above the diagonal in Figure 2) whereas risks come from "unproductive frictions" between the diverse components (area below the diagonal). The evaluation is boiled down to just one typical strength and weakness of each cluster. Face-to-face tools like, for example, group discussions or bilateral discussions often have a strong impact on the motivation by offering the possibility to give immediate and personalized feedbacks and by satisfying social needs. These advantages, however, come along with high costs for traveling to physical meetings, workshops or seminars. Electronic tools like e-mail or intranet portals typically have a broad reach, since they are able to deliver information quickly and easily to geographically dispersed employees, team members, or customers affected by the change. However, this broadcasting bears the risk of social deprivation of the actors involved because emotional feedbacks in the change process are impaired. Thus, electronic tools often leave social needs as well as security needs unsatisfied and fail in dealing with confusion, anxieties, and other typical effects of change.

Tool blending attains synergy effects in terms of richness and reach of communication when simultaneous communication via intranet and workshops is applied. Compensation of weaknesses by strengths of the additional tool is reached when the time needed for seminars can be reduced by providing general basic information via electronic media prior to the onsite seminars. One category of risk caused by blending is conflict: Providing redundant content by print and by electronic media may provoke a conflict with project budget restrictions. Incompatibility may even cause chaos, for instance when contradictory content is delivered via electronic media and physical meetings respectively. This may be due to the fact that electronic media are normally more up-to-date whereas print media often distribute obsolete data in turbulent change processes.

\subsection{Patterns of Tool Blending}

\subsubsection{Dimensions of Blending Patterns}

To analyze, categorize and design blended toolboxes a multidimensional approach is needed that is based on three parameters of blending:

Scope: This dimension covers the quantitative aspects of blending, i.e. the number of tools incorporated in the blended toolbox and the proportions of blending, i.e. the ratio of percentage of use of the tools in question. 50:50-proportions stand for balanced blending while an 80:20-ratio indicates the dominance of one tool category.

Diversity: A combination of workshops, flyers, meetings and a letter from the CEO in the employees' magazine characterize homogeneous blending since all tools in the list rely on conventional communication via physical 
meetings or print media. The level of diversity increases when both face-to-face tools and electronic media (e.g. e-mail, virtual communities and weblogs) are used. Diversity stems from contrast between tools (heterogeneous blending), since electronic media, unlike face-to-face change management, go along with asynchronous communication and lack a direct contact between the participating players.

Coupling: Blending ranges from loose to tight coupling of tools. In the case of loose coupling, change managers pick different tools out of a blended toolbox to be applied in distinct sectors or stages of the change project. By this strictly separated handling, tools can be adjusted to different segments of the context (e.g. different target groups like employees versus temporary manpower, top management versus lower management), preferences of clients (reflecting their respective corporate culture) and modules of the change concept (e.g. redesigned business processes, organization charts, incentives systems, lay-offs). From a rational management point of view this corresponds to the idea of contingent management with respect to tool utilization. Likewise, face-to-face communication in the pilot phase can be combined with electronic communication in the roll out-phase which allows an adjustment to the size of the respective target groups.

Tight coupling is either related to toolboxes in terms of blended menus or blended bundles. Blended menus offer at least two tools (e.g. e-mail or telephone, print media or electronic newsletters, physical workshops or virtual meeting on internet community platforms) as alternative options. Providing menus is client-friendly but quite costly: Since tools are not pre-selected within a contingent change management approach (i.e. loose coupling), the entire range of diverse options has to be provided until employees or clients make their choices.

In blended bundles, tight coupling is performed in a "total" fashion yielding new genuinely hybrid tools that incorporate both genes of their parent tools: Project meetings are not either face-to-face or virtual, but semivirtual with some team members participating physically, others virtually via videoconferencing. Communication is neither purely top-down nor bottom-up, but takes place in an iterative down-up process.

Each of the three dimensions also serves as a scale to measure the level of hybridity of tool blending. So a broad, balanced scope of heterogeneous and tightly coupled tool bundles represents the maximum challenge for change managers because the performance of the blended toolbox cannot be easily traced back to the strengths and weaknesses of the tool components in question. Focused, unbalanced homogeneous and loosely coupled toolboxes on the other hand are by far easier to understand and to evaluate.

\subsubsection{Engineered and Emergent Patterns}

Like strategies, structures, systems or other building blocks of management, toolboxes are either the result of deliberate planning (engineered patterns of blending) or the result of unplanned activities (emergent patterns of blending) or possibly a (hybrid) combination of both, in the tradition of hybrid process models like guided evolution, logical incrementalism, organic rationality or organized anarchy.

Engineered patterns of blending are created by a rational planning process. The objective of this process is achieving an optimal opportunity-risk ratio. This is accomplished by aggregating the weighed positive and negative evaluations of blended concepts (see Figure 2). The aggregation has to consider reciprocal interaction effects triggered by the tension between the components of a hybrid toolbox.

Emergent patterns of blending are not determined by rational procedures of evaluation and design. Like in all other fields of management, change managers are not necessarily guided by the rational evaluation of opportunities and risks. There are many other factors that influence blending activities. Some of them are apparently irrational from the standpoint of rational optimization. A prominent example is "change management follows fashion", with "hypes" (quite common in the lifecycle of electronic trends [18]) representing an extreme species of fashion. However, go-with-the-flow behavior in change management may have definitely rational advantages for the situation of the individual manager [19]. The long list of factors influencing the behavior of change managers contains many personal factors such as

1) expertise in change management, e.g. number of change projects managed in the past.

2) personal preferences for tools: preferences may be a matter of familiarity with tools or even an expression of a dogmatic approach when for instance orthodox disciples of OD refuse to adopt Business Process Reengineering tools because of a cultural misfit.

3) lack of skill in handling specific tools.

4) avoidance of risk: Cautiousness may also make change managers refrain from tool blending which very likely provokes some risks (see Figure 2).

5) variety seeking: Openness to new tools and trends. This experimental approach is sometimes reflected in randomly composed toolboxes.

To assess the respective relevance of rational and personal determinants of tool blending and the resulting relevance of engineered or emergent patterns respectively, empirical investigation is required. Existing analyses are non-empirical, empirical but focused on the range of complementary tools or focused on single tools (not on toolboxes) or empirical but case study-based providing evidence that lacks representativeness. 


\section{Empirical Investigation of Blending Patterns}

\subsection{Survey Design}

To examine the "real world" patterns of tool blending, the department of organizational behavior at Stuttgart University conducted an online survey amongst German, Swiss and Austrian change experts in first quarter of 2008. In addition to this, a weblog (http://www.changezweinull.de) was installed to enable a virtual sharing and exchange of knowledge. The arena of tool blending examined was the configuration of non-electronic and electronic tools. The tools were clustered into two groups: face-to-face tools (workshops, multiplicators, top management commitment, employee magazines, seminars, brochures/folders/flyers, bilateral talks) and electronic tools (virtual communities/internet forums, intranet portals, information videos, e-mail newsletter, web-based trainings, podcasts/webcasts, individual weblogs, social networking platforms, wikis, and corporate weblogs). The web 2.0 tools investigated are individual weblogs, corporate weblogs, wikis, social networking platforms and podcasts/webcasts. This selection reflects the common web 2.0 tools [20-23].

The majority of respondents were contacted directly via personalized e-mails. The respondents were asked to forward the e-mail to other change managers among their colleagues and clients. Furthermore, a link to the survey was integrated in several electronic newsletters. The project weblog also provided the possibility to take part in the survey. With 305 respondents the return rate (as percentage of the number of mails sent) is $15.5 \%$.

Almost half of the respondents are consultants, less than a fourth of the respondents are academic staff and faculty, and approximately one sixth of the respondents are employed in manufacturing or service companies.

Change managers (people who have already managed change projects) cover almost three fourths of the respondents. Within this group, a majority of change managers has managed between six and 50 projects and can be regarded as well-experienced in change management. Change managers who have managed more than 50 projects account for only $4.3 \%$. A look at the change expertise focusing the spectrum of change categories shows that $45 \%$ of all change projects are restructuring projects, followed by strategy shift projects with approximately one third of all projects. 30\% of the participating change managers predominantly manage business process reengineering and cultural change projects respectively. Approximately $20 \%$ of the change managers are regularly involved in the management of IT implementation projects. The survey investigated mainly a) the incidence of face-to-face and electronic change management tools in change management and b) the existing patterns of blending as well as their determinants.

\subsection{Results}

Scope of tool blending: The survey supports the assumption that the use of multiple change management tools is standard. More than $70 \%$ of the respondents use at least four tools in change management frequently or always. Almost 9\% use ten or more instruments at least frequently. Only $35 \%$ of the respondents use two or more electronic media frequently or always. When the answers "frequently" and "sometimes" are aggregated, more than $70 \%$ of the respondents use at least two electronic tools in change management.

Diversity of tool blending: From the data, three basic types of blended toolboxes can be distinguished with respect to the diversity of blending: Focused toolboxes are used by change managers who concentrate on a particular "core cluster" of tools (here: face-to-face tools). These managers are reluctant to blending and consequently do not use any instrument from the other cluster. In blended toolboxes a distinction between a primary cluster and a secondary cluster is not feasible. The respective change managers do not have a clear preference for one of the two groups but use tools from both groups frequently. Change managers working with ad hoc toolboxes do not use any tool more frequently than "sometimes". Apparently, there is no preference for one cluster of tools among these change managers. Rather, these change managers configure their toolboxes randomly. Table 1 demonstrates the respective frequencies of toolboxes in the sample.

Differentiating the instruments used with respect to the cluster they belong to shows-not surprisingly-that merely one respondent focuses solely on electronic tools, while $31 \%$ focus on face-to-face instruments in change management. Blended toolboxes represent the biggest portion in the sample (67\%), whereas ad-hoc mixes account for only $2.7 \%$.

The simple assignment of the respondents to one of the two patterns specified by level of diversity (focused and blended mixes) ignores the scope dimension of blending. A valid measure of the hybridity of blending ("blending index") must encompass both diversity and scope. The focused as well as the blended patterns are more hybrid when they are based on a larger number of change management tools. Hence, the scope dimension was differentiated into "narrow", "medium", and "broad" (see Table 2).

Using the blending index, the following types of patterns can be distinguished according to their respective degree of diversity: narrow focused (1), medium focused (2), medium blended (3), and broad blended toolboxes (4).

A look at the frequencies of the different patterns reveals a peculiar result: only $7 \%$ of the change managers in the sample put a narrow focus on face-to-face instruments, i.e. use three different tools frequently at the most. 
Table 1. Frequencies of blended patterns

\begin{tabular}{|c|c|c|c|c|c|}
\hline \multirow{2}{*}{\multicolumn{2}{|c|}{$\begin{array}{l}\text { Scope } \\
\text { (total number of tools used) }\end{array}$}} & \multicolumn{2}{|l|}{ Diversity } & \multirow[b]{2}{*}{ Total } & \multirow[b]{2}{*}{$\begin{array}{l}\text { Ad-hoc } \\
\text { toolboxes }\end{array}$} \\
\hline & & $\begin{array}{l}\text { Focused } \\
\text { toolboxes }\end{array}$ & $\begin{array}{l}\text { Blended } \\
\text { toolboxes }\end{array}$ & & \\
\hline All instruments & $\begin{array}{l}1 \\
2 \\
3 \\
4 \\
5 \\
6 \\
7 \\
8 \\
9 \\
10 \\
11 \\
12 \\
13 \\
14 \\
16\end{array}$ & $\begin{array}{l}2 \\
3 \\
10 \\
17 \\
23 \\
12 \\
0 \\
0 \\
0 \\
0 \\
0 \\
0 \\
0 \\
0 \\
0\end{array}$ & $\begin{array}{l}0 \\
0 \\
0 \\
9 \\
16 \\
25 \\
24 \\
26 \\
22 \\
7 \\
8 \\
6 \\
2 \\
1 \\
1\end{array}$ & $\begin{array}{l}2 \\
3 \\
10 \\
26 \\
39 \\
37 \\
24 \\
26 \\
22 \\
7 \\
8 \\
6 \\
2 \\
1 \\
1\end{array}$ & \\
\hline \multicolumn{2}{|l|}{ Total } & $\begin{array}{l}67 \\
(30.5 \%)\end{array}$ & $\begin{array}{l}147 \\
(67 \%)\end{array}$ & $\begin{array}{l}214 \\
(97 \%)\end{array}$ & $\begin{array}{l}6 \\
(2.7 \%)\end{array}$ \\
\hline
\end{tabular}

Obviously, a broad scope of tools is essential for change management. Tool blending as opposed to focusing is only practiced when at least four tools are used frequently. In the medium section of the scope dimension (four to six tools) the respondents almost evenly disperse to the two "extreme" categories focused and blended toolboxes, while there exist no focused patterns for seven instruments or more at all. The currently great importance of tool blending is furthermore confirmed by the large portion of broad blended toolboxes (more than six instruments are used frequently).

Coupling patterns: Factor analyses and regression analyses were conducted to find out what context factors lead to specific patterns of blending in general and of coupling in particular. The set of determinants examined that presumably impact coupling patterns contains task oriented and person oriented factors. Task-oriented determinants analyzed were:

- change categories (the two categories of change projects managed most frequently)

- $\quad$ industry (within which change projects are managed)

- $\quad$ project size in terms of employees affected (number of employees affected)

- $\quad$ project size in terms of project manpower (number of project team members)

Three person-oriented determinants were integrated into statistical analysis:

- $\quad$ expertise (number of change projects managed)

- occupation of the respondents

- blending mindset: Personal assessment of the interaction between face-to-face change management tools and electronic tools, representing some- 
Table 2. Typology of blended toolboxes

\begin{tabular}{|c|c|c|c|c|}
\hline & & $\begin{array}{l}\text { scope } \\
\text { (focused t } \\
\text { blended to }\end{array}$ & & \\
\hline & & focused & blended & total \\
\hline $\begin{array}{l}\text { diversity } \\
\text { (all }\end{array}$ & $\begin{array}{l}\text { narrow } \\
\text { (1 to } 3 \text { tools) }\end{array}$ & $\begin{array}{l}15 \\
(7 \%)\end{array}$ & $\begin{array}{l}0 \\
(0 \%)\end{array}$ & $\begin{array}{l}15 \\
(7 \%)\end{array}$ \\
\hline tools) & $\begin{array}{l}\text { medium } \\
\text { (4 to } 6 \text { tools) }\end{array}$ & $\begin{array}{l}52 \\
(24.3 \%)\end{array}$ & $\begin{array}{l}50 \\
(23.4 \%)\end{array}$ & $\begin{array}{l}102 \\
(47.7 \%)\end{array}$ \\
\hline & $\begin{array}{l}\text { broad } \\
\text { (7 or more tools) }\end{array}$ & $\begin{array}{l}0 \\
(0 \%)\end{array}$ & $\begin{array}{l}97 \\
(45.3 \%)\end{array}$ & $\begin{array}{l}97 \\
(45.3 \%)\end{array}$ \\
\hline total & & $\begin{array}{l}67 \\
(31.3 \%)\end{array}$ & $\begin{array}{l}147 \\
(68.7 \%)\end{array}$ & $\begin{array}{l}214 \\
(100 \%)\end{array}$ \\
\hline
\end{tabular}

thing like a personal "blending theory". The respondents ranked these tool relationships on a scale ranging from "complementing” to "crowding out" of tools.

Table 3 illustrates that there is a relatively high positive and statistically significant correlation between project size (number of employees affected) and the blending index. Apparently, there is a tendency to focus on few instruments in smaller projects, while large projects trigger extensive blending in the use of change management tools. This corresponds to the definition of loose coupling via context segmentation ("different target groups require different tools”). On the one hand, the complementary use of electronic tools is probably required by the increasing demand for reach in large projects. Such enhancement of change management reach can only be accomplished efficiently by using internet-based media. On the other hand, effectiveness also requires more intensive blending in large-scale projects in terms of large number of employees affected. Along with the number of targeted employees, the diversity in this group of employees also increases. This heterogene- ity can be dealt with by using a broad range of change management tools to enable individualization of change management activities, i.e. to adjust these activities to the needs and preferences of the respective employees and other target groups.

The project manpower, i.e. the number of team members, also correlates positively with the blending index, although less strongly and less significantly. Partly, this is due to the relationship between the number of employees affected and the requisite size of project teams which (not surprisingly) turns out to be statistically significant. Moreover, the number of team members also has an immediate impact on the blending of instruments: on the one hand, electronic tools are mandatory to warrant the reach of change management activities. On the other hand, the project requires a higher richness of change management toolboxes to cope with the increased need for individualization.

The analysis of correlation revealed another counterintuitive relationship between a context variable and the blending index: the personal assessments of the interaction between electronic tools and face-to-face change 
Table 3. Correlations between context variables and blending index

\begin{tabular}{|c|c|c|c|c|c|c|c|c|c|}
\hline & & $\begin{array}{c}\text { Blending } \\
\text { index }\end{array}$ & $\begin{array}{c}\text { Ocupa- } \\
\text { tion }\end{array}$ & $\begin{array}{c}\text { Number } \\
\text { of pro- } \\
\text { jects }\end{array}$ & Industry & $\begin{array}{l}\text { Employ- } \\
\text { ees af- } \\
\text { fected }\end{array}$ & $\begin{array}{l}\text { Project } \\
\text { man- } \\
\text { power }\end{array}$ & $\begin{array}{c}\text { Interac- } \\
\text { tion }\end{array}$ & $\begin{array}{c}\text { Change } \\
\text { Catego- } \\
\text { ries }\end{array}$ \\
\hline $\begin{array}{l}\text { Corre- } \\
\text { lation }\end{array}$ & $\begin{array}{c}\text { Blending } \\
\text { Index }\end{array}$ & & $\begin{array}{l}-, 007 \\
\text { (n.s.) }\end{array}$ & $\begin{array}{l}, 013 \\
\text { (n.s.) }\end{array}$ & $\begin{array}{l}-, 086 \\
\text { (n.s.) }\end{array}$ & $\begin{array}{l}\text {,289 } \\
(, 000)\end{array}$ & $\begin{array}{l}, 150 \\
(, 039)\end{array}$ & $\begin{array}{l}-, 168 \\
(, 024)\end{array}$ & $\begin{array}{l}, 003 \\
\text { (n.s.) }\end{array}$ \\
\hline & Occupation & & & $\begin{array}{l}-, 398 \\
(, 000)\end{array}$ & $\begin{array}{l}127 \\
(, 069)\end{array}$ & $\begin{array}{l}-, 114 \\
(\mathrm{n} . \mathrm{s})\end{array}$ & $\begin{array}{l}-, 127 \\
(0,69)\end{array}$ & $\begin{array}{l}, 069 \\
\text { (n.s.) }\end{array}$ & $\begin{array}{l}, 075 \\
\text { (n.s.) }\end{array}$ \\
\hline & $\begin{array}{c}\text { Number of } \\
\text { projects }\end{array}$ & & & & $\begin{array}{l}-, 151 \\
(, 038)\end{array}$ & $\begin{array}{l}\text {,096 } \\
\text { (n.s.) }\end{array}$ & $\begin{array}{l}, 141 \\
(, 040)\end{array}$ & $\begin{array}{l}-, 006 \\
\text { (n.s.) }\end{array}$ & $\begin{array}{l}\text {,101 } \\
\text { (n.s.) }\end{array}$ \\
\hline & Industry & & & & & $\begin{array}{l}-, 140 \\
(, 050)\end{array}$ & $\begin{array}{l}-, 116 \\
\text { (n.s.) }\end{array}$ & $\begin{array}{l}, 075 \\
\text { (n.s.) }\end{array}$ & $\begin{array}{l}-, 021 \\
\text { (n.s.) }\end{array}$ \\
\hline & $\begin{array}{c}\text { Employees } \\
\text { affected }\end{array}$ & & & & & & $\begin{array}{l}, 412 \\
(, 000)\end{array}$ & $\begin{array}{l}-, 016 \\
(\mathrm{n} . \mathrm{s})\end{array}$ & $\begin{array}{l}-, 077 \\
\text { (n.s.) }\end{array}$ \\
\hline & $\begin{array}{c}\text { Project } \\
\text { manpower }\end{array}$ & & & & & & & $\begin{array}{l}-, 030 \\
\text { (n.s.) }\end{array}$ & $\begin{array}{l}-, 052 \\
\text { (n.s.) }\end{array}$ \\
\hline & Interaction & & & & & & & & $\begin{array}{l}-, 032 \\
\text { (n.s) }\end{array}$ \\
\hline & $\begin{array}{c}\text { Change } \\
\text { categories }\end{array}$ & & & & & & & & \\
\hline
\end{tabular}

management and the blending index have a slightly negative correlation. In other words, those change managers who assume a harmonic complementary relationship between the two groups of instruments (in Figure 2 above the diagonal) still tend to focus on one group of instruments-and thus do not exploit the opportunities of blended tool boxes. This is most likely caused by context barriers, such as a lack of technical infrastructures, of familiarity with tools, and/or by budget restrictions. Tight budget restrictions are not only a problem in small projects. All varieties of change are currently exposed to a high pressure for efficiency [10]. Also, whenever change managers experience a low degree of acceptance for such media amongst the employees affected, they may refrain from deploying these instruments, although they assume a harmonic relationship with other change management tools.

In addition to correlations between the blending index and task-or person-oriented context factors, interrelations among the context variables were examined. For this investigation, a factor analysis was conducted to discover underlying factor structures. The factor analysis yielded three components (see Table 4) which account together for an explained variance of 53.1\%.

The first factor-on which the variables blending index, number of employees affected and number of team members are loading-represents the project size. The structure of this component shows that large projects require electronic change management tools and that these instruments are always used in combination with face-to-face tools. In turn, this structure also shows that the use of blended toolboxes is not based on individual tool preferences of change managers or employees affected. The application of blended toolboxes is rather driven by project requirements - in particular by project size-and thus aims to compensate the weaknesses of many a change management tool (see Figure 2).

The second factor (change expertise)_consisting of the variables occupation and number of change projectsdoes not contain the blending index. The structure of this factor is plausible: The occupation of the change managers affects the number of projects managed. For example, 
Table 4. Component diagramm (rotated component matrix)

\begin{tabular}{|l|l|l|l|}
\hline & \multicolumn{2}{l|}{ Component } \\
\hline & $\mathbf{1}$ & $\mathbf{2}$ & $\mathbf{3}$ \\
\hline Blending index &, 562 & &, 473 \\
\hline Occupation & &, 778 & \\
\hline Number of projects & &,- 822 & \\
\hline Industry & &, 356 & \\
\hline Employees affected &, 805 & & \\
\hline Project manpower &, 703 & & \\
\hline Interaction & & &,- 711 \\
\hline Change categories &,- 314 & &, 559 \\
\hline
\end{tabular}

Note: extraction method: principal component analysis. Rotation method: Varimax with Kaiser-normalization, explained variance: $53.1 \%$. The results of the rotated component matrix are considered.

Factor 1 (Project size): Blending index, employees affected, project manpower

Faktor 2 (Change expertise): occupation, number of projects

Faktor 3 (Evaluation): Blending index, interaction

consultants are "full-time” change managers and thus typically have ample change experience, while managers in other industries are less experienced in change management.

The third factor (evaluation) captures the assessment of the interaction between face-to-face change management and electronic media as well as the blending index. It does not deliver an explanation for blending practices that is as obvious as the one provided by the first factor. The negative correlation between the two variables (interaction and blending index) has to be explained by context factors not covered by the survey. On the one hand, this correlation can be explained by some additional barriers to the use of blended toolboxes. On the other hand, dynamics of toolbox design can be held responsible for this phenomenon: The majority (204 persons or $87.6 \%$ ) of the respondents diagnose a crowding-out relationship between face-to-face change management and electronic tools. More than half of these 204 respondents already use blended toolboxes. The statement that the two groups of instruments crowd each other out may derive from the assumption that the future brings a migration from face-to-face change management to electronic media, in other words a step-by-step shift of proportions in favor of new electronic tools. This interpretation gets further support from the respondents' opinion concerning the future relevance of web 2.0-tools in change management toolboxes. While most respon- dents (64.9\%) estimate the current percentage of web 2.0 tools-application in change management to be less than $10 \%, 82 \%$ expect this share to rise in the future. That means the vast majority of the participating experts expects an increasing importance of electronic media in change management.

\section{Conclusions and Outlook}

There is evidence provided by the survey that blended change management is a reality reflected in blended toolboxes. The majority of change managers advocate tool blending. Only a minority concentrate on familiar face-to-face tools. Tool blending is predominantly guided by rational considerations: task features are more relevant than personal preferences (such as affinity to technology or conservative tendencies towards familiar instruments) or experience. The scope, diversity and coupling of tool blending primarily depend on project size: Large-scale projects drive the use of several different change management tools whereas small projects tend to be focused on face-to-face change management. The identified blending patterns are generic; they are in particular not influenced by specific change categories. The opportunities of blended toolboxes assessed by the experts are currently not sufficiently exploited. In particular, situational restrictions in the application of change management tools constrain the diffusion of new electronic tools, although the experts assume a harmonic complementary relationship between these tools and face-to-face change management activities. The experts' assessments outline a tool scenario that is characterized by blended toolboxes with an increasing share of electronic change management tools. This trend gets more momentum when new hybrid tools such as augmented reality [24,25] will be applied in the training of interpersonal and not only technical skills. Unlike virtual reality (e.g. avatars), these hybrid tools operate on an extremely tight coupling of virtuality and reality. Simulations of typical constellations in change processes (e.g. conflict resolution, postmerger integration, coopetitive arrangements within networks) that are normally dealt with in physical role playing and business theatre [13] up to date could profit considerably from these sophisticated blended tools.

\section{REFERENCES}

[1] IBM Global Business Services, Making Change Work, 2008,

https://www.ibm.com/services/de/bcs/pdf/2007/making_c hange_work.pdf.

[2] Kotter, J. P., "Leading change, Why transformation efforts fail,” Harvard Business Review, No. 73, pp. 59-67, 1995.

[3] Gerkhardt, M. and Frey, D., "Erfolgsfaktoren und psychologische Hintergründe in Veränderungsprozessen,” Zeitschrift für Organisationsentwicklung, No. 4, pp. 48-59, 2006.

[4] Greif, S., Runde, B., and Seeberg, J., "Erfolge und Mis- 
serfolge beim, Change Management,” Hogrefe, Göttingen, 2004.

[5] Cawsey, T. F. and Deszca, G., "Toolkit for organizational change,” Sage, Thousand Oaks, 2008.

[6] Wunderer, R. and Bruch, H., "Umsetzungskompetenz, Diagnose und Förderung in Theorie und Unternehmenspraxis,” Vahlen, München, 2000.

[7] Helfat, C. E., et al., "Dynamic capabilities: Understanding strategic change in organizations,” Malden, Blackwell, MA, 2007.

[8] Hughes, M., "The tools and techniques of change management,” Journal of Change Management, Vol. 7, No. 1, pp. 37-49, 2007.

[9] Orthey, F. M., “Tools, tools, tools, Ein Beitrag über die 'Vertoolisierung' und 'Baumarktmentalität' in der Trainings- und Beratungsarbeit,” Zeitschrift für Organisationsentwicklung, No. 4, pp. 73-75, 2007.

[10] Capgemini, "Change management 2003/2008, significance, strategies, trends,” 2008, http://www.capgemini.com.

[11] Thorne, K., "Blended learning: How to integrate online \& traditional learning,” Kogan Page, London, 2003.

[12] Blom, H. A. and Lygeros, J., "Stochastic hybrid systems,” Theory and Safety Critical Applications, Springer, Berlin, 2006.

[13] Cornelissen, J. P., "What are we playing at? Theatre, organization, and the use of metaphor," Organization Studies, Vol. 25, No. 5, pp. 705-726, 2004.

[14] Klarner, P. and Raisch, S., "Organisationalen Wandel messen, Erfolgreiche Veränderungen setzen geeignete Messinstrumente voraus, Ein Überblick zu Messinstrumenten des organisationalen Wandels und ihrer Einsatzgebiete," Zeitschrift für Organisationsentwicklung, No. 4, pp. 4-13, 2007.
[15] Pitt, L., Murgolo-Poore, M., and Dix, S., "Changing change management: The intranet as catalyst,” Journal of Change Management, Vol. 2, No. 2, pp. 106-114, 2001.

[16] Lewis, M. and Maylor, H., "Game playing and operations management education,” International Journal of Production Economics, No. 105, pp. 134-149, 2007.

[17] Fong, J., Reggie, K., and Wang, F. L., "Hybrid learning and education,” Springer, Berlin-Heidelberg, 2008.

[18] Gartner Group, “Understanding hype-cycle,” 2008, http://www.gartner.com/pages/story.php.id.8795.s.8.jsp.

[19] Kieser, A., "Moden und Mythen des Organisierens,” Die Betriebswirtschaft, Vol. 56, No. 1, pp. 21-39, 1996.

[20] Anderson, P., "What is web 2.0? Ideas, technologies and implications for education," 2007, http://www.jisc.ac.uk/media/documents/techwatch/tsw07 01b.pdf.

[21] Ebersbach, A., Glaser, M., and Heigl, R., "Wiki: Web collaboration,” Springer, Berlin, 2006.

[22] McAfee, A., "Enterprise 2.0. the dawn of emergent collaboration," MIT Sloan Management Review, Vol. 47, No. 3, pp. 20-28, 2006.

[23] O’Reilly, T., "What is web 2.0? Design patterns and business models for the next generation of software," 2005,

http://www.oreillynet.com/pub/a/oreilly/tim/news/2005/0 9/30/what-is-web-20.

[24] Milgram, P. and Kishino, F., "A taxonomy of mixed reality visual displays," IEICE Transactions on Information Systems, Vol. E77-D, No. 12, December 1994.

[25] Billinghurst, M. and Kato, H., "Collaborative augmented reality," Communications of the ACM, Vol. 45, No. 7, pp. 64-70, 2002. 